\title{
Signaling with the Eyebrows - Commentary on Huron, Dahl, and Johnson
}

\author{
JOHN OHALA \\ University of California, Berkeley
}

\begin{abstract}
Huron, Dahl, and Johnson, in their paper "Facial Expression and Vocal Pitch Height: Evidence of an Intermodal Association", demonstrated a positive correlation between the pitch of a sung note and the vertical position of the singer's eyebrows. Moreover, other subjects viewing photographs of the faces of the singers, with the lower part of the face and neck of the singers blocked out, could accurately judge whether a high note or low note had been sung. The authors offer a number of hypothetical explanations for their findings. I propose a speculative, ethologically-based, explanation for these correlations: namely, how both pitch of voice and eyebrow position would be correlated in this way to convey to the viewer the degree of potential threat - or lack of threat - posed by the signaler.
\end{abstract}

Submitted 2009 October 1; accepted 2009 October 12.

KEYWORDS: pitch height, facial expression, aggression, intermodal perception

IF there were an index specifying the ratio of the scientific significance of a study over the steps involved in it, Huron, Dahl, and Johnson's (2009) demonstration of an association of facial expressions with voice pitch would merit a very high number. The relative simplicity of the experimental design and the straightforward statistical analysis makes it very convincing and ripe for explanation. The authors entertain various admittedly speculative hypotheses to account for the results: from a learned association, to some sort of physiological link between facial expressions and the action of the larynx. I venture here to offer another admittedly speculative explanation.

As reviewed by the authors, Morton (1977) demonstrated a cross-species and cross-class (i.e., birds and mammals) similarity in the characteristics of agonistic vocalizations, i.e., those involved in confrontations or competitions: low fundamental frequency (F0) and a tendency towards aperiodicity for threat and tone-like high F0 calls for appeasement or non-threat. As he reasoned, these vocal characteristics help to convey an impression - even if it may be a deceitful impression - of the size of the vocalizer and thus the degree of potential threat that they pose to their antagonist. Is there any way that the position of the eyebrows can have the same function, i.e., convey to an antagonist an impression of the degree of threat posed? I believe that there is.

First, one is motivated to look for such a link because brow movement is found in other species as well, notably, canids, for which the literature is particularly good, especially since one member of that family is our 'best friend', the dog, and since both humans and canids have a plastic facial mask, that is, both are endowed with an elaborate array of muscles capable of deforming the facial cover. As it happens, canids raise and lower their brows in non-threatening and threatening signals, respectively. Moreover this gesture is part of a multi-modal array of signals, as listed in Table 1.

\begin{tabular}{|l|l|l|}
\hline & Threat & Non-threat = submission, appeasement \\
\hline 1 & Ears erect & Ears flattened \\
\hline 2 & Tail erect & Tail between the legs \\
\hline 3 & Piloerections (hair raised on back) & Absence of piloerection \\
\hline 4 & Standing tall and stiff-legged & Crouching \\
\hline 5 & An aperiodic, low F0, vocalization (a.k.a. "growl") & A tone-like, high F0, vocalization (a.k.a. "whine") \\
\hline 6 & $\begin{array}{l}\text { Mouth rounded, revealing teeth only as far back as } \\
\text { the canines }\end{array}$ & $\begin{array}{l}\text { Mouth corners retracted, revealing all the teeth, } \\
\text { including those further back than the canines }\end{array}$ \\
\hline 7 & Lowered brows & Raised brows \\
\hline
\end{tabular}

Table 1. Multi-modal array of signals. 
Nos. 1-4 uncontroversially serve to give an impression of the size of the signaler to the viewer ("size" here includes the angle subtended in the visual field). Morton (1977) and Ohala (1984) have argued that nos. 5 and 6 , respectively, can convey an impression of size of the signaler - in the latter case when these mouth shapes are accompanied by a vocalization. Assuming, for the sake of argument, that if no. 7 - altering the elevation of the brows - is to augment these other aspects of a "size signal", we are led to ask how and why this is done.

The answer may be found in the common experience that newborns - both humans and non-humans - have relatively large eyes. This is not just an illusion. Human infants' eyes grow disproportionately less than other anatomical structures, including the head they are embedded in. This is part of nature's strategy to keep images in focus on the retina. Experiments done on animals and "nature's experiment" when cataracts or other eye defects prevent focused images on the retina in one eye show that the affected eye exhibits abnormal growth. Therefore a gesture that makes the eyes seem larger will convey to the viewer that the owner is less mature and therefore less of a threat. Conversely, conveying an impression of small eyes will augment a signal that the owner is more mature and thus more of a threat. It might be objected that in the case of humans, raising or lowering the eyebrows does not significantly affect the apparent size of the eyes themselves since the eyebrows are not the actual perimeter of the eyes. But, I suggest, the position of the eyebrows may convey an impression of the size of the eyes. I acknowledge that this claim is an empirical issue and that it has not as yet been subjected to experimental evaluation.

In Ohala (2009) I have presented other evidence, including a rationale for certain forms of cosmetic modification of the appearance of the eyes, eye lashes, and eyebrows in support of the above speculative hypothesis.

It is reasonable to suppose that all elements of signals as functionally important as threat and non-threat should work together to mutually reinforce each other. This, and the fact that many elements of such a multi-modal signal are manifest cross-species and cross family, leads us to the conclusion that implementation of such signals and the reaction of viewers to them is probably not learned but innate. But this, too, needs further empirical study.

Another index of the significance of a scientific paper would be the number of further scientific works it leads to. Here, again, Huron and colleagues, like Morton (1977), merit a high rating.

\section{REFERENCES}

Huron, D., Dahl, S., \& Johnson, R. (2009). Facial expression and vocal pitch height: Evidence of an intermodal association. Empirical Musicology Review, 4(3): 93-100.

Ohala, J. J. (2009). The ethological basis of certain signals of affect and emotion. In: S. Hancil (ed.), The role of prosody in affective speech. Bern: Peter Lang, pp. 17-30. 